\title{
DIALOGUE
}

\section{Commentary on "Social Facts, Moral Regulation and Statistical Jurisdiction: A Critical Evaluation of Canadian Census Figures on Education"}

\author{
GORDON PRIEST*
}

The Shamai/Corrigan article, "Social Facts, Moral Regulation and Statistical Jurisdiction: A Critical Evaluation of Canadian Census Figures on Education" (The Canadian Journal of Higher Education, Vol. XVII-2, 1987) presents a challenge in precisely determining the real intention of the authors. The title promises an evaluation of the Canadian census figures on education while the abstract promises that the "bulk of the paper consists of an examination of trends in ethnicity and gender in relation to varying measures of educational achievement". The Introduction, however, suggests that the paper "explores biases in educational data collected by Statistics Canada" and then goes on to discuss the authority of the state in the collection of data and implies that the state then may abuse the data.

While Shamai and Corrigan have much to say about objectivity and bias in data it is unfortunate that their own discussion is so encumbered by the literary trick of casting suspicion upon certain words through highlighting by the use of italics or quotation marks. For example, why in the opening pages of the article have the authors chosen to highlight in this manner words such as "neutral", "objective", "without any bias", [rulers and state authorities ... counting 'their' people], [the determination of who are 'our people'], 'the State', [the 'Right' ... to collect a range of statistical information], "social facts", ['document' reality], ['produce' the data], very selective, 'descriptive facts' and 'neutral institutions'? Is it that the authors wished to imply, rather than state in a substantive way, that statistical agencies, such as Statistics Canada, are not neutral, are not objective but are biased and fabricate social fiction rather than social facts?

In spite of the ambiguity of titles, abstracts and introductions perhaps what Shamai and Corrigan are really getting at is summed up in their statement that:

"It is usually difficult to point out if and how official statisitics, including Statistics Canada, use their power. Like Foucault we believe power is never more powerful when it is rendered relatively invisible in seemingly 'descriptive facts' produced by 'neutral institutions'."

Errors in logic or grammar aside, the above statement would seem to imply that Statistics Canada might be suspected of a misuse of power because it is not neutral. 
And so we come to the point that it appears that the authors really wish to make, that is, that Statistics Canada has been party to some complex, longstanding state conspiracy resulting in "an historical legacy of biased presentation".

If the authors wish to make a serious effort to prove such a point they will have to abandon their naïve perspective and prepare to engage in a great deal more substantive research than they have demonstrated in the paper in question. For example, on pages 39 and 40 they list "the different stages of processing the data". They note that the first stage is "the decision about what is ... relevant ... to be surveyed" and the second stage is "the wording of the question and the variable's definition". The classification of the data is described as being performed at a much later stage, after enumeration. In fact, the classification of the data is determined much earlier, and under ideal circumstances is done at the very earliest stages in consultation with the clients. In fact, the proper approach to survey development is to determine the clients' needs in terms of tabular output or data base classifications to satisfy their research requirements. A failure to recognize this fundamental step at an early stage can lead to subsequent problems in processing specifications or even in asking the wrong questions on the survey vehicle. To use the approach cited by Shamai and Corrigan would be akin to attempting to build a house without ever having first drawn the plans.

A further example of naïvety is seen in the discussion of the presentation of 1931 Census data which reflects an apparent ignorance of both a fundamental rule of social anthropology and the realities of data collection and presentation. Even first year university students know that objective historical, anthropological and social studies are never made from the perspective of the observer's societal values. Therefore, to understand the presentation of the 1931 Census data we need to understand the values, mores, issues and indeed, the common lexicon of the day. Shamai and Corrigan have failed to consider this but rather have used today's values in judging the use, in 1931, of terms like racial groups. Furthermore, with respect to the selective use of certain terms, data collection (and hence data presentation) is driven very much by the lexicon of the day since the questions asked must be readily understood by all respondents. Today in Canada we would be quite outraged by a line of questioning that attempted to determine if the respondent was a half-breed. Yet in 1941 that line of questioning was used because it was a term that was then used in the common lexicon and commonly accepted, much as the term Métis would be now. Therefore, terminology used in 1931 data output was heavily influenced by the use of terminology in the collection process that would be readily understood by respondents.

Certainly, a legitimate criticism of Census data, or any other historical data series for that matter, is that an historical comparison is often made difficult because of changing concepts, definitions or classifications. The statistician continually faces two legitimate but contradictory objectives. One is to maintain historical comparability at all costs. The other is to be relevant to the current environment and current needs. To satisfy both objectives would render a data collection vehicle so burdensome and costly that it would be totally unrealistic. 
Thus compromise is the only course but with it comes certain costs in terms of lost utility. The serious student of historical statistics, is of course, aware of such constraints and accounts for such in his or her analysis.

It is unfortunate that Shamai and Corrigan did not make a more thorough review of the development of state statistical systems and that they did not present their review in a more objective light. There are indeed substantial Biblical and historical references to the state census and such activity was often in support of the raising of taxes or armies or both. The census activity of Jean Talon in New France was unique in that it is one of the earliest examples of a census being taken, not for the above-noted reasons, but to facilitate the informed economic, demographic and social planning of a collective society. That principle has become fundamental to most modern statistical systems in most enlightened countries and indeed in the statistical activities of the United Nations. At a recent international meeting a high ranking official of the government of the People's Republic of China noted that the greatest single cause of the failure of economic, social and demographic reforms following the Revolution was the lack of comprehensive objective statistics, on the nation and its people, to ensure informed decision making. Thus we have cause for concern that state statistical systems are objective, unbiased and as accurate as possible. It is also important that state statistical agencies are not only objective (and we might add relevant) but that they are also seen to be objective.

While the Shamai/Corrigan paper is unclear in its stated purpose, superficial in its investigation and confused in its presentation it does serve to remind those of us who are part of Canada's statistical system of how easily society can be misinformed regarding the objectivity of the agency. Statistics Canada has deliberately embarked upon programs that openly discuss the quality of the data and it is unfortunate that Shamai and Corrigan did not make a fuller use of such reference materials (e.g., A Users Guide to 1981 Ethnic Origin Data, Boxhill, 1986). It is also unfortunate that Shamai and Corrigan were apparently unaware of the series of coast to coast public forums Statistics Canada has recently conducted to determine societal needs for data to be obtained from the 1991 Census. Agency planners would have welcomed hearing first hand their views.

\section{Response by Dr. Shmuel Shamai and Professor Philip Corrigan}

Whilst we, as with all authors, welcome any discussion concerning any and all of our arguments and evidence; we were surprised to read Gordon E. Priest's response to our article 'Social Facts, Moral Regulation and Statistical Jurisdiction' (CJHE, XVII, 2, 1987, 37-58) because we fail to see the logic of his critique, insofar as it illustrates exactly what we (amongst many others) have argued about Statistical Power(s). It is also, and in significant ways, full of contradictions.

He states that our article is vague, but it is clear that one feature of our 'message' comes through, to him (and his colleagues), 'loud and clear': State-istics (to use an orthography that traces the power/knowledge relations) are a form of power. They are, moreover, a structured form of power. This means that his accusation against 
us - for implying that data gathering, processing, managing and publication, are 'biased' (and that this implies some 'bad faith' or 'malfeance' on the part of individuals) - is totally misplaced. Indeed the extensiveness of his accusation against us - that we claim that Statistics Canada (and other statistical agencies) 'fabricate social fiction' - is itself typical of the very issues which we were trying to explicate, as they also indicate his lack of 'care' when making such an unfounded accusation whose genealogy is in fact in an individualist perception of society.

Nothing we have written in our article, or in other writings, implies that we doubt that there are 'beyond' (as it were) censal data, social facts, as Priest rightly claims. We follow an extensive tradition, begun most coherently with Durkheim (cf P. Corrigan 'On Moral Regulation' Sociological Review, 29, 1981; D. Frisby and D. Sayer, Society, Methuen, 1986) that social facts are themselves the result of human agency in making meaningful, in particular ways, some randomly associated features or qualities of social realities as signs that stand for the totality of such facts, and 'stand' not simply indexically but also evaluatively (for one case study that concerns, precisely, 'the facts' see Shmuel Shamai and Yoram Bar-Gel 'The Swamps of the Jezreel Valley', Sociologia Internationalis, XIII, 2, 1987; for more extensive treatment see Dorothy Smith, The Everyday World as Problematic. Toronto, University of Toronto Press, 1988).

'Bias' is indeed not the key term of the structuration of a (dominant) version of reality, anymore than 'prejudice' (as attitude) or 'discrimination' (as agency) help to clarify institutional racism. Here Priest's mention of the relation between (statistical) agency and 'clients' is a key confirmation of our argument. Who, exactly, are the clients for the Census of Canada? Since writing the article one of us (Corrigan) has been bombarded by statements about the value of Censal data for ... whom exactly? Well, it seems that what Statistics Canada provides is 'decision data' for 'MARKET RESEARCH FIRMS ... URBAN PLANNERS ... SOCIAL SERVICE AGENCIES ... THE ACADEMIC COMMUNITY' because 'Wise business decisions don't just happen' (Letter from David Roy, Commercial Activities, Statistics Canada, February 1988, orthography as original). In the same month a letter was received addressed to 'Dear Client' which informed 'us' (interpellated by this nostrum of 'being a client') that 'At Statistics Canada we collect, package and publish a wide range of vital economic and social data ... important to managers, to analysts, and to marketers'. The enclosed 'Memorandum' was addressed to 'PLANNERS AND DECISION-MAKERS' and headed, for the first section, 'Tracking the money spenders'; it also included an invitation to join the CANSIM Mini-base (privatised to independent distributors) or to buy floppy discs from the CANSIM Main Base. What kind of clientage relationship is in mind here; statistics of whom, for whom, by whom?

We are further accused of naïveté in various ways. For example, we impute 1980 s values onto the categories and arrangement of the 1931 census data. Priest states: 'data collection (and hence data presentation) is driven very much by the lexicon of the day since the questions asked must be readily understood by all 
respondents.' This implies - and it really is quite scandalous for this to be presumed in 1987-88 - there was no struggle around the meaning of racist (and sexist) terms in the 1930 s, or that subsequent generations are morally denied the right to criticise the realities and events of those with the power to determine 'social facts' in previous generations. In an article authored by Jewish and Irish writers we argued for that moral right to re-flect and re-vision and say that $\mathrm{X}$ or $\mathrm{Y}$ or $\mathrm{Z}$ was wrong! Otherwise we subjugate ourselves (and all others) to a contemporary morality. It is also naïve - for a statistician - to concentrate upon and highlight the lexicon, when it is the organising grammar (of sign, inference, referentiality and subsequent locutionary and illocutionary utterance) that produces the surface phenomena (see any text by the later Wittgenstein, especially $O n$ Certainty).

One of us at least would take the most exceptional distance from Priest's claim that "the greatest single cause of the failure of economic, social and demographic reforms following the Revolution [in the People's Republic of China] was the lack of comprehensive objective statistics ...' (Corrigan, Ramsay, Sayer: Socialist construction and Marxist theory, Macmillan, 1978; For Mao, Macmillan, 1979; 'Bolshevism and the Soviet Union', New Left Review, 121, 1981; Corrigan and Sayer, 'Socialist Reconstruction and Marxist Theory in Historical Perspective', Utafiti. Dar Es Salaam, Summer 1984). But we would both say - exactly, this proves our point, that there is no neutral way of declaring a population (and its characteristics) to be such and such, which is not imbricated in power-knowledge relations, forms of ruling and the general moral and social organization of knowledge. State-istics are a form of cartography (they are, in fact, a cartogrammar) in which some people are empowered to declare that they know more than the people on the ground, who know their way round without maps (see any of the Cambridge Studies in Historical Geography, the journal Antipode, or the work of David Harvey).

In sum, all we are and were saying is that State-istics are motivated, they embody (literally 'figure') interests, of those who can authorise the count(ing) - of which Statistics Canada, in Priest's account, are agents - and not of those who are counted. 'Who, whom?' remains the basic political algorithm of our time, the kernel social algebra. We would like to thank Gordon Priest (and his colleagues) for their time and for their writing. We find that his text manifests the power and subjectivity of statistical data (of that 'Statistical Idea' invented in France and England in the late 18th and early 19th century and transplanted to British North America, cf B. Curtis, Building the Educational State: Canada West. 1836-1871. (London, Althouse Press, 1987; R. Morgan, The cultural production of English in Ontario, PhD Thesis, University of Toronto, 1987; P. Corrigan (ed.), Ontario State Formation, 1870-1970, forthcoming; not to mention M.C. Urquhart 'Three Builders of Canada's Statistical System', Canadian Historical Review, LXVIII, 3, 1987 or G. Emery 'Ontario's Civil Registration of Vital Statistics, 1869-1926', Ibid., LXIV, 4, 1983 or R. R. Kuczynski, Birth Registration and Birth Statistics in Canada (Washington, DC., Brookings Institute, 1930). 
However we also stressed in our article, indeed in many ways it was its raison d'etre, that such materials - whatever their genealogy, provenance and structuration - can be re-read (indeed, re-visioned) in ways which reveal, critically, trends and patterns which we living in this present 1980s) need to know to understand that crucial social linkage between the past and the future. Re-visioning such data (not least that which, despite electronic data bases, Statistics Canada has never quite managed to make public) shows that any image of steady homogeneous progress falls apart on the solid 'social fact' of difference. This set of identifying disadvantages which have almost nothing to do with Statistics Canada but which, in the manner of its depiction (and in the recent orientation to certain customers for the resulting data), can be made less salient, and thus less scandalously immoral than might be the case. That is all. 